\title{
Um debate sobre o Estado logístico, subimperialismo e imperialismo brasileiro
}

\section{Debate on the state logistics Brazilian sub-imperialism and imperialism}

\author{
Caio Martins Bugiato \\ bugiato@hotmail.com \\ Tatiana Berringer \\ berringer.tatiana@gmail.com \\ Doutorandos em Ciência Política pela Universidade Estadual de Campinas (UNICAMP)
}

\begin{abstract}
Resumo:
Nos últimos anos o Estado brasileiro obteve índices favoráveis no que se referem as suas relações econômicas internacionais. O Estado fomentou o crescimento dos investimentos do país no exterior, tendo como financiador desse processo o Banco Nacional de Desenvolvimento Econômico e Social (BNDES). A inserção do país de forma mais expressiva na economia mundial trouxe à baila interpretações sobre o papel do Estado brasileiro na condução de sua política externa. Assim, neste texto apresentamos três teses sobre a inserção brasileira no cenário internacional: a tese do Estado logístico, a tese do subimperialismo brasileiro a tese do imperialismo brasileiro. Ao final do texto, apontamos algumas insuficiências destas teses e temas que necessitam de reflexões mais apuradas para que se possa entender o papel do Estado brasileiro no cenário internacional neste início de século XXI.
\end{abstract}

Palavras-chave: Estado. Política externa. Imperialismo. Subimperialismo. BNDES.

\begin{abstract}
:
In the last years the brazilian state has had positive indices in its international economic relations. The state has promoted the grow of the investments of the country abroad by the aid of Banco Nacional de Desenvolvimento Economico e Social (BNDES), the supporter of this process. Tha insertion of the country in a more expressive way in the world economy has evoked interpretations about the hole of the brazilian state in conducting its foreign policy. Thus, we present three thesis about the brazilian insertion in the international scenery: the thesis about the logistic states, the thesis about the brazilian subimperialism and the thesis about the brazilian imperialism. At the end of the text, we indicate some insufficiencies of these thesis and themes that need more elaborated reflections in order to understand the hole of the brazilian state in the international scenery in the beginning of the 21 th century.
\end{abstract}

Keywords: State. Foreign policy. Imperailism. Subimperialism. BNDES.

Originais recebidos em: 20/03/2012

Aceito para publicação em: 04/06/2012

Este trabalho está licenciado sob uma Licença Creative Commons Atribuição-Uso NãoComercial-Vedada a criação de obras derivadas 3.0 Unported License. 


\section{A inserção do Estado brasileiro no cenário internacional}

Na primeira década do século XXI, sobretudo nos anos do governo de Luis Inácio Lula da Silva (2003-2010), o Estrado brasileiro se destacou na cena política internacional, passando a ocupar um espaço importante nos principais fóruns e organizações internacionais, entre eles: a criação do G-20 na Organização Mundial do Comércio (OMC), a criação da UNASUR (União das Nações Sul-americanas), a participação da missão de paz da Organização das Nações Unidas no Haiti MINUSTAH (Mission des Nations Unies pour la stabilisation en Haïti) -, a coalizão IBSA - Brasil, Índia e África do Sul, entre outros. Acompanhando esse destaque, houve um aumento da inserção brasileira na economia mundial por meio das atividades de suas empresas no exterior. As empresas com origem no Brasil não só cresceram, mas se internacionalizaram, em busca de novos mercados e ganharam importância no cenário internacional e na política externa brasileira. Já há em território brasileiro quase mil empresas com presença relevante no exterior - com mais de $10 \%$ do capital de filiais e investimento direto superior a US\$ 10 milhões -, das quais as mais internacionalizadas são: JBS, Marfrig, Brasil Foods, Oderbrecht, Camargo Correa, Gerdau, CSN, Coteminas, Vale, Fibria, Sabó, Ambev, Artecola, Tigre, Embraer, Marcopolo, Petrobras, entre outras. (SOBEET/VALOR ECONOMICO, 2009) ${ }^{1}$.

As empresas transnacionais brasileiras possuem investimentos principalmente nos ramos da agricultura, da pecuária e de recursos naturais, nos ramos de bens de consumo como alimentos, bebidas e têxteis, de bens intermediários como produtos químicos e equipamentos e da construção civil e no comércio e no transporte, com destaque para as atuações lucrativas em recursos naturais, construção civil e alimentos. Atualmente estão presentes em todo o globo. Vejamos a distribuição geográfica das empresas brasileiras no exterior no gráfico 1 abaixo:

\footnotetext{
${ }^{1}$ Nesse texto são apresentadas as empresas brasileiras - controladas por acionistas ou proprietários nacionais - internacionalizadas, ou empresas transnacionais. O índice para classificá-las como empresas internacionalizadas é calculado pela participação de empregos, ativos e receitas das empresas no exterior em relação aos números gerais (metodologia definida pela Conferencia das Nações Unidas sobre Comércio e Desenvolvimento, UNCTAD).

Em Debat: Rev. Dig., ISSNe 1980-3532, Florianópolis, n. 7, p. 28-44, jan-jul, 2012.
} 


\section{Gráfico 1- Distribuição geográfica das transnacionais brasileiras}

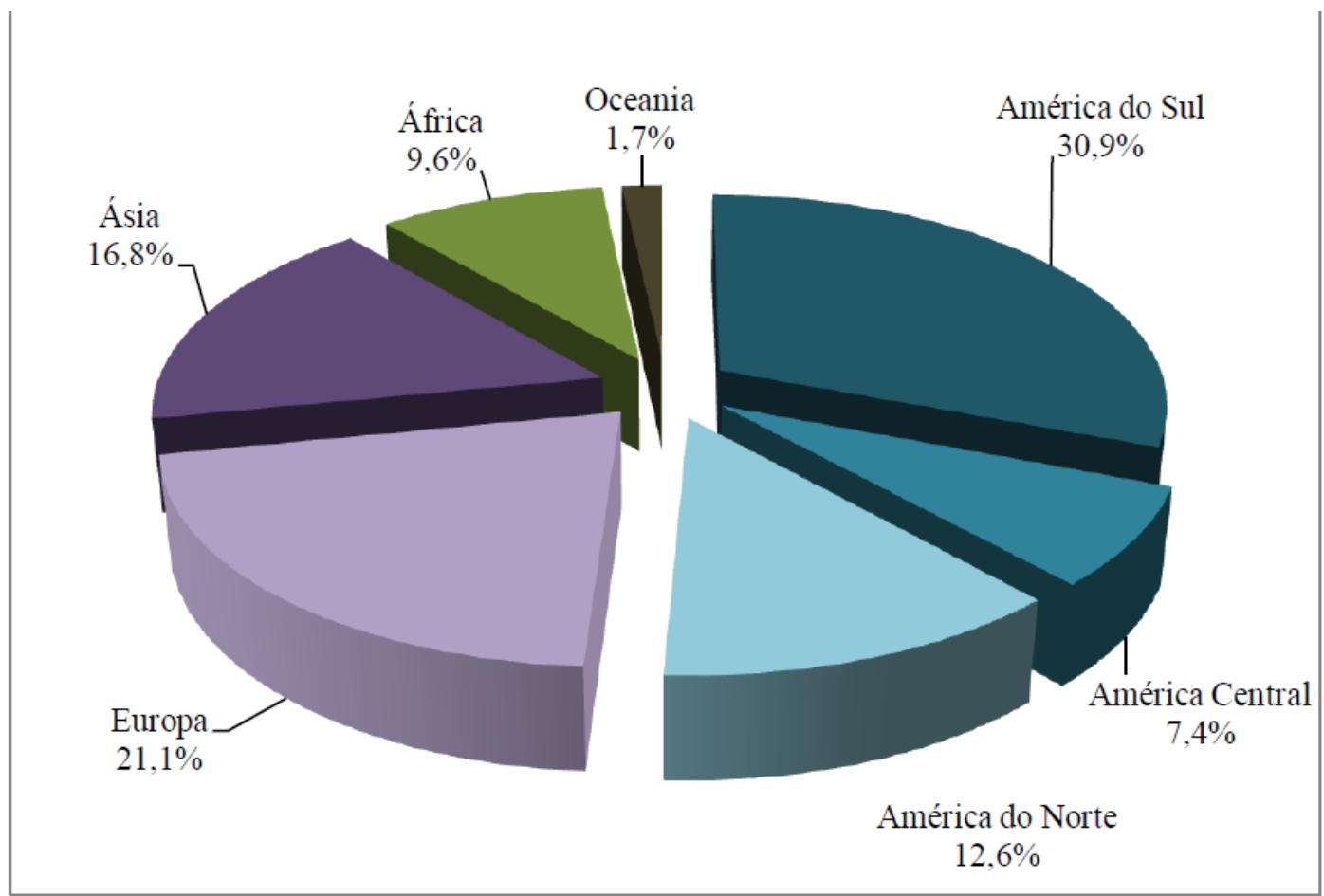

Fonte: Ranking das Transnacionais Brasileiras 2011 - FDC

Embora o território brasileiro esteja entre os principais destinos de investimentos internacionais, o país tem se destacado nos últimos anos como exportador de capitais. Em 2006, pela primeira vez na história, o volume de investimentos brasileiros diretos no exterior ultrapassou o volume de investimentos estrangeiros no país. Os investimentos diretos brasileiros no exterior atingiram a marca de US\$32,3 bilhões no ano de 2006. Esta marca colocou o país na $12^{\mathrm{a}}$ posição no ranking dos maiores investidores do mundo, superando países como Austrália, Rússia e Suécia. Os recursos que saíram do país a título de investimento direto externo no ano de 2006 aumentaram 49,4\% em relação ao montante do ano de 2005 e 129,46\% em relação a 2001, quando um estudo desse caráter foi conduzido pela primeira vez pelo Banco Central (KPMG, 2008). As aquisições e fusões envolvendo empresas brasileiras cresceram e em 2007 estabeleceram recorde, com crescimento expressivo de 48\% em relação ao ano anterior, sendo contabilizadas 66 operações dessa natureza. Os investimentos diretos brasileiros 
no exterior acumularam entre 2000 e 2008 mais de sete vezes o volume de toda a década de 1990 (Banco Central do Brasil), ${ }^{2}$ conforme tabela abaixo:

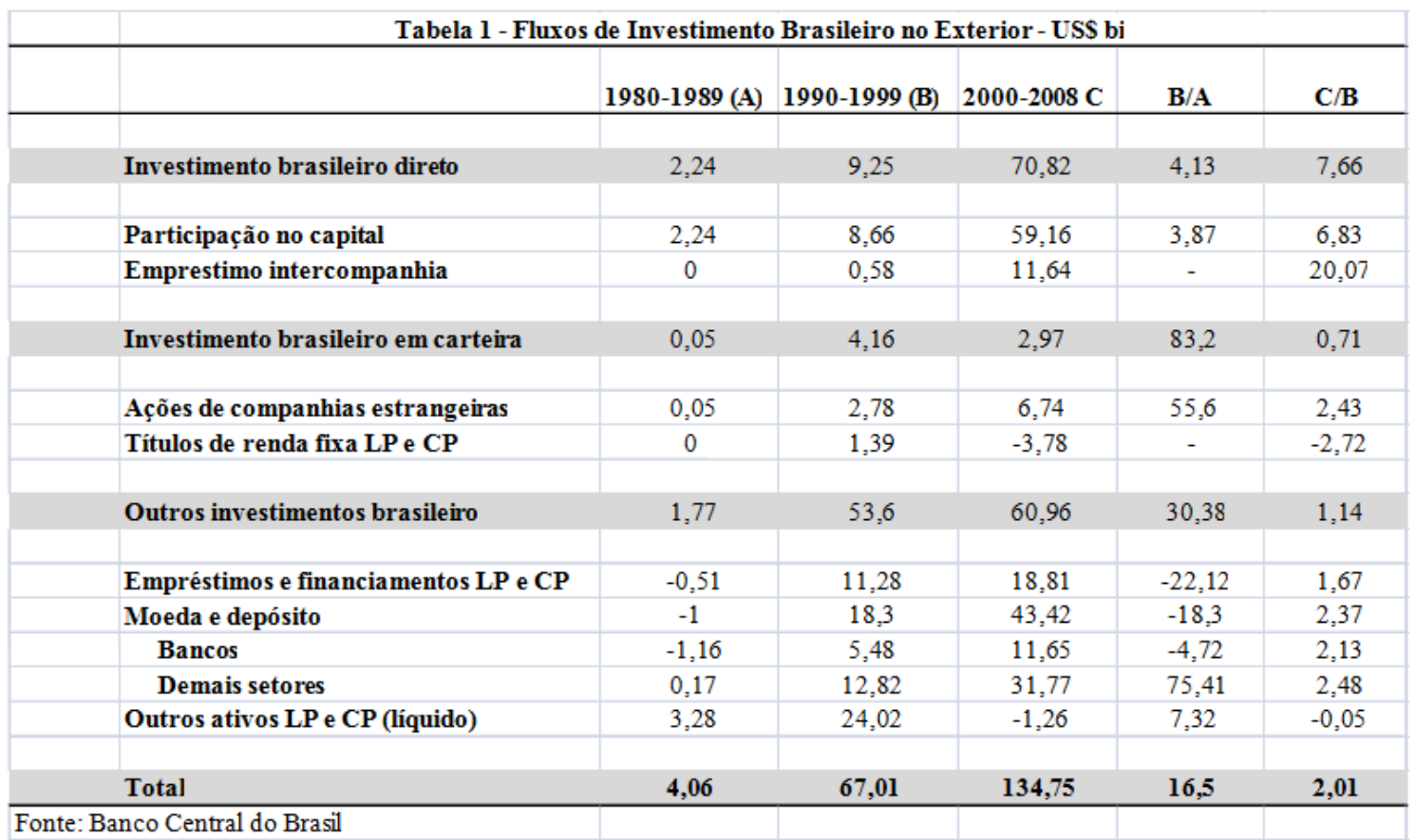

Cumpre dizer que o Banco Nacional de Desenvolvimento Econômico e Social (BNDES) foi decisivo para a internacionalização de empresas. Com linhas de crédito e participação acionária, o banco promoveu o investimento das empresas brasileiras no exterior. É expressivo o número de empresas nacionais que atuam no exterior que possuem a BNDESPar (BNDES Participações, subsidiária do BNDES) como acionista; compreendem setores como agropecuária, energia elétrica, telecomunicações, mineração, bancos, papel, petroquímica, siderurgia, transportes e aviação. Em 2010 a BNDESPar tinha porcentagem no capital de: América Latina Logística (12,21\%), Gerdau (3,50\%), Banco do Brasil (2,43\%), Itaú Holding (0,25\%), JBS Friboi (17,32\%), Bradesco (0,25\%), Klabin (20,25\%), Brasil Foods (2,55\%), Light (22,96\%), Brasil Telecom (2,20\%), Marfrig (13,89\%), MPX Energia (2,60\%), Braskem (5,55\%), CEG $(34,56 \%)$, CPFL Energia (8,42\%), Petrobras (7,66\%), Cia. Siderúrgica Nacional $(2,10 \%)$, Eletrobrás (18,50\%), Embraer (5,37\%), Vale S/A (5,34\%) e Fibria $(30,42 \%)$, entre outras (VALDEZ, 2011).

\footnotetext{
2 “[...] considera-se um investimento estrangeiro como investimento direto quando o investidor detém $10 \%$ ou mais das ações ordinárias ou do direito de voto numa empresa. Esse critério, embora arbitrário, foi adotado porque estima-se que tal participação seja um investimento a longo prazo, permitindo a seu proprietário exercer influência sobre as decisões de gestão da empresa. Já um investimento estrangeiro inferior a 10\% será contabilizado com investimento em carteira" (CHESNAIS, 1996, p.33).

Em Debat: Rev. Dig., ISSNe 1980-3532, Florianópolis, n. 7, p. 28-44, jan-jul, 2012.
} 
No exterior o BNDES tem dado suporte às aquisições das empresas brasileiras. No Uruguai, a Marfig e a (JBS) Friboi controlam cerca de 70\% da exportação da carne uruguaia. Na Argentina, a Petrobras adquiriu a Pecom e se tornou o segundo grupo econômico do país no setor de petróleo e gás; a Ambev comprou a Quilmes; a Camargo Correa comprou a maior fábrica de cimento do país, a Loma Negra; e a (JBS) Friboi adquiriu as unidades da Swift na Argentina, tornando-se o maior frigorífico do mundo. No Peru, a Votorantim (hoje Fibria) comprou a maior mineradora do país, MinCo, que tem $66 \%$ das jazidas nacionais; a Gerdau comprou a SiderPeru, maior siderúrgica peruana; e a Petrobras/Pecom é a segunda maior produtora de petróleo no país (NOVOA, 2009). Afora, O banco criou uma subsidiária em Montevidéu para tratar da América do Sul.

A América Latina é o mercado principal de atuação das grandes empresas brasileiras. Dos US\$ 56 bilhões em ativos produtivos no exterior que as empresas brasileiras tinham em 2006, metade se traduz em investimento na América Latina. Apesar do investimento direto brasileiro representar apenas 2,3\% dos investimentos mundiais, na América do Sul a participação do investimento direto brasileiro vem crescendo ano após ano. Como aponta a pesquisa da Confederação Nacional das Indústrias, a estratégia das empresas brasileiras para a região tem sido a implementação de novas plantas (greenfield projects). Dos 20 maiores projetos de novas plantas das empresas brasileiras, 14 se concentram na América do Sul e um na América Central. Embora a Argentina seja até o momento o principal destino na região, devido ao tamanho de seu mercado e às facilidades geradas pela integração no âmbito do Mercosul, já há empresas brasileiras atuando no mercados de Bolívia, Chile, Colômbia, Equador e Peru (IGLESIAS, 2007).

O BNDES não apoia apenas empresas, mas também projetos de infra-estrutura. $\mathrm{O}$ aumento tanto dos fluxos de investimento quanto dos de comércio sul-sul confirmam a particular relevância de uma estratégia de internacionalização associada aos projetos de integração regional. A IIRSA (Iniciativa para la Integración de la Infraestructura Regional Suramericana) é um projeto conjunto de doze países da América do Sul para a construção de uma infra-estrutura de comunicações, transportes e geração de energia que constitui um sistema de circulação de capitais e mercadorias, permitindo dessa forma entrelaçar as economias regionais ao mercado mundial. A IIRSA é um projeto de integração do mercado sul-americano para lhe dar maior competitividade em relação a outras regiões (ALEM E CAVALCANTI, 2005). Entre os 31 projetos que compõem a Em Debat: Rev. Dig., ISSNe 1980-3532, Florianópolis, n. 7, p. 28-44, jan-jul, 2012. 
Agenda de Implementação Consensual da IIRSA, o Estado brasileiro tem participação em 9, além disso há outros projetos brasileiros que foram incorporados ao Programa de Aceleração de Crescimento 2 (PAC2).

Esta presença das empresas brasileiras na América Latina e em outras formações sociais periféricas e o papel geopolítico do Estado brasileiro passaram a ser a preocupação e o estudo de intelectuais e políticos brasileiros. Há um rico debate que busca problematizar a atuação internacional brasileira. Nesse debate podemos identificar três teses sobre a inserção brasileira no cenário internacional, que serão apresentadas a seguir: a tese do Estado logístico e o desenvolvimento nacional, a tese do subimperialismo brasileiro a tese do imperialismo brasileiro.

\section{O Estado logístico e o desenvolvimento nacional}

O conceito de Estado logístico é de Amado Luis Cervo (2002). De acordo com este autor, a partir das mudanças ocorridas no cenário internacional com a queda do World Trade Center em 2001 e a crise financeira internacional, no Brasil se teria iniciado a construção do ele chama de Estado logístico. O governo de Fernando Henrique Cardoso já buscara estreitar o relacionamento com a China, Índia e África do Sul e pleiteara um equilíbrio nas negociações econômicas internacionais, como na Área de Livre Comércio das Américas (ALCA). No entanto, foi no governo Lula que se fortaleceram as alianças com os países periféricos - principalmente na América do Sul e se concretizou uma política externa de enfrentamento as regras e normas dos países centrais nas negociações comerciais.

Segundo Cervo (2002), o Estado logístico é o Estado que tem por objetivo o fortalecimento da nação, uma vez que este passa a responsabilidade do papel de empreendedor à sociedade, ampara as operações externas e auxilia a inserção no sistema internacional, tendo sempre em vista o desenvolvimento nacional e a maximização das oportunidades oferecidas pelo sistema internacional. Através do auxílio do BNDES, o Estado busca “dar apoio logístico aos empreendimentos, o público e o privado, de preferência o privado, com o fim de robustecê-lo em termos comparativos internacionais" (CERVO, 2007, p.87). Essa ideia limita a casos pontuais e a setores estratégicos o investimento estatal, mas não o rejeita. Dessa forma, o Estado brasileiro mobiliza seu aparato institucional com a finalidade de oferecer melhores condições para 
a inserção internacional da economia brasileira ao garantir auxílio financeiro ao empresariado nacional. ${ }^{3}$

Partindo do conceito de Cervo, Valdez (2011) desenvolve sua tese sobre a inserção do país no cenário internacional durante o governo Lula. Para Valdez, a diversificação de parceiros internacionais da política externa brasileira de Lula abriu maiores possibilidades para a ação brasileira no cenário externo. $\mathrm{O}$ autor chama a atenção para a formação do G-20, que atua no âmbito da OMC e em outras discussões comerciais e financeiras internacionais. Tal diversificação foi um dos principais fatores de uma política externa autônoma do governo, uma vez que esta contribuiu para a reformulação de regras internacionais, retirando o país de uma posição subordinada e favorecendo o desenvolvimento nacional. ${ }^{4}$

De acordo com Valdez (2011), para promover a inserção internacional brasileira, Lula utilizou o BNDES como principal financiador do desenvolvimento nacional, cuja tática principal foi o apoio à construção da infraestrutura sul-americana (IIRSA) e à internacionalização das empresas brasileiras. Tendo o BNDES por trás destas duas frentes táticas, o governo Lula fortaleceu o papel logístico do Estado brasileiro de agente indutor do desenvolvimento nacional, criando um relacionamento estreito entre o Estado logístico e o empresariado nacional, que se complementa no âmbito da política externo do país.

Para o autor, essa inserção evidencia a convergência entre a política econômica e a política externa de Lula. A política do BNDES de financiamento às empresas nacionais e o consequente dinamismo empresarial desses atores internos estão diretamente ligados à prioridade que a política externa deu a América do Sul, onde a inserção dessas empresas teve mais êxito. Os recursos do BNDES à IIRSA também fazem parte dessa convergência, dado que a construção de uma infraestrutura sulamericana beneficia os negócios das empresas brasileiras.

\footnotetext{
${ }^{3}$ Cervo opera com tipologias de Estado para caracterizar a política externa brasileira. Segundo ele, de 1930 a 1980 prevaleceu no Brasil o "Estado desenvolvimentista", o qual se caracteriza pela autonomia da política externa e tem como foco a busca pelo desenvolvimento econômico nacional como forma de romper com a dependência econômica brasileira. Esse modelo teria sido abandonado pelos governos neoliberais a partir de 1990 devido a uma maior submissão ao centro hegemônico do capitalismo e a dissolução da economia nacional. O Estado nesse contexto seria caracterizado pelo autor como "Estado normal", isto é, subserviente aos mandos hegemônicos. O Estado logístico corresponde ao atual momento, mais precisamente, aos governos Lula.

${ }^{4} \mathrm{O}$ conceito de desenvolvimento nacional não é aprofundado pelo autor. Entretanto, pode-se inferir do seu texto que este conceito está relacionado ao crescimento econômico por si só, ou seja, aos índices de elevação do produto interno bruto.

Em Debat: Rev. Dig., ISSNe 1980-3532, Florianópolis, n. 7, p. 28-44, jan-jul, 2012.
} 
Segundo Valdez (2011), a convergência entre a política econômica e a política externa do governo foi parte da estratégia de estabilidade econômica e da retomada do papel do Estado em um projeto neodesenvolvimentista ${ }^{5}$. Nesse contexto, BNDES agiu como grande articulador no fomento a empresas globais competitivas. Para o autor, a convergência da política econômica com a política externa do Estado logístico brasileiro contempla interesses mútuos: de um lado o Estado promove o desenvolvimento nacional e de outro o empresariado expande seus negócios, podendo este ser considerado o ator principal da política externa brasileira.

\section{O subimperialismo brasileiro}

Mathias Luce (2007) resgata o conceito de subimperialismo de Ruy Mauro Marini para explicar a atual inserção brasileira no cenário internacional. De acordo com Marini (1977; 1980), a essência da economia brasileira se reflete na política externa do país e tal essência é a dependência, propriedade histórica da formação social brasileira. Os principais fatores da dependência são a inibição da demanda efetiva interna e a redução do excedente econômico a ser investido, os quais impedem o desenvolvimento capitalista autônomo ao reduzir o mercado consumidor e a capacidade de importar maquinário. Essa situação resulta na integração da burguesia brasileira ao circuito econômico internacional de forma subordinada, a fim de levar adiante a industrialização no país. Dessa forma, Marini atribui à economia brasileira dependente a característica de composição orgânica média de capital, o que, grosso modo, significa pequena participação do produto manufaturado no produto interno bruto de um país.

A posição intermediária da economia brasileira na divisão internacional do trabalho é acompanhada pelo engajamento do Estado em promover uma política expansionista relativamente autônoma: de um lado se cria uma área de influência regional própria - América do Sul - que corresponde aos interesses da burguesia brasileira, que, de outro lado está submetida aos laços de dependência do capital estrangeiro - principalmente dos Estados Unidos. Assim sendo, Marini (1977; 1980) denomina essa interação entre a economia dependente (de composição orgânica média de capital) e a política externa (expansionista e relativamente autônoma) de

\footnotetext{
${ }^{5}$ O prefixo "neo" é utilizado para diferenciar o período desenvolvimentista de 1930 a 1989 da época atual, cuja novidade é a inserção no mercado externo como fator de desenvolvimento econômico (crescimento do PIB) do país.

Em Debat: Rev. Dig., ISSNe 1980-3532, Florianópolis, n. 7, p. 28-44, jan-jul, 2012.
} 
subimperialismo, ou seja, a entrada do Estado brasileiro de modo dependente e subordinado à etapa de exportação de capital e manufaturas e controle de matériasprimas e fontes de energia no exterior.

Definimos [...] o subimperialismo como a forma que assume a economia dependente ao chegar à etapa dos monopólios e do capital financeiro. $\mathrm{O}$ subimperialismo implica dois componentes básicos: por um lado, uma composição orgânica média [de capital] na escala mundial dos aparatos produtivos nacionais, e por outro, o exercício de uma política expansionista relativamente autônoma, que não só se acompanha de uma maior integração ao sistema produtivo imperialista, mas que se mantém no marco da hegemonia exercida pelo imperialismo em escala internacional (MARINI, 1977, p. 31).

Para entender a dinâmica do conceito de subimperialismo, Marini (1980) desenvolveu a categoria cooperação antagônica. Tomando como ponto de partida a integração da estrutura produtiva brasileira ao imperialismo, a cooperação antagônica é a dinâmica das contradições entre a formação social dependente e a hegemônica, na qual aquela estabelece uma relação de dependência com esta, ao mesmo tempo em que se choca continuamente com esta, em seu desejo de extrair maiores vantagens no processo de divisão internacional do trabalho no qual estão imersas. A formação social dependente, ao perseguir a construção de hegemonia regional, entra em atrito com o centro hegemônico. Os contenciosos são uma forma de barganha por concessão e manutenção de áreas de influência e os instrumentos desses dissensos são a possibilidade a formar alianças alternativas, posse de recursos estratégicos ou capacidade de estabilização da ordem na região. Contudo, os laços de dependência são um freio para essa política externa, o que a torna relativamente autônoma. $\mathrm{O}$ traço característico da cooperação antagônica é a acomodação dos atritos nos marcos da hegemonia da formação social dominante.

De acordo com Luce (2007), a política externa brasileira dos governos de Lula leva traços significativos de uma política subimperialista, sobretudo no que se refere à cooperação antagônica. Sob a presidência de Lula, o Estado brasileiro não consentiu com as políticas de Washington em uma série de oportunidades: o governo arquivou as negociações da Área de Livre Comércio das Américas, remetendo a Organização Mundial do Comércio temas sensíveis à economia brasileira, como a abertura de mercado para o agronegócio brasileiro; formou o G-20 na OMC, recusando-se a negociar temas nos quais não se tratava da redução dos subsídios agrícolas, na rodada de Cancún; participou assertivamente da construção da IIRSA, com volumosos financiamentos do BNDES, para garantir infraestrutura para a atuação de empresas Em Debat: Rev. Dig., ISSNe 1980-3532, Florianópolis, n. 7, p. 28-44, jan-jul, 2012. 
brasileira; criticou a invasão unilateral do Iraque em 2003; retirou do congresso nacional o projeto de lei sobre a concessão da base militar de Alcântara às forças armadas dos Estados Unidos e negou concessão de outras bases para o Plano Colômbia; e atuou como mediador regional nas crises políticas do Equador em 2005, entre Venezuela e Colômbia, também em 2005, e em Honduras em 2009, a fím de evitar ingerência externa e, no caso do Equador, garantir os interesses de empresas nacionais nos países, como a Petrobras. O governo de Lula igualmente corroborou o imperialismo estadunidense: aprovou o cultivo de transgênicos, interessante a empresas dos EUA; na rodada da OMC de Hong Kong, aceitou reduzir tarifas aduaneiras sobre produtos industrializados e avançar na negociação de serviços em troca da promessa de diminuição dos subsídios agrícolas; atuou como negociador regional para uma saída pacífica para a crise política na Bolívia em 2003, garantindo os interesses da Petrobras ao preservar a institucionalidade vigente e impedindo a ascensão de forças antiimperialistas; não condenou a invasão e o golpe de Estado pela força militar francoestadunidense no Haiti e liderou a MINUSTAH para demonstrar capacidade militar e se habilitar a uma vaga permanente no Conselho de Segurança.

Luce (2007) destaca como traços principais do subimperialismo brasileiro a inserção das empresas brasileiras no cenário internacional, bem como a construção da IIRSA. Tal inserção é feita por empresas brasileiras que atuam em setores de baixo valor agregado, como alimentos e recursos naturais. Concomitantemente, empresas estrangeiras, sobretudo estadunidenses, encontram em território brasileiro um ambiente propício para instalar plataformas de exportação para seus produtos, como nos casos das empresas de eletrodomésticos e das montadoras de automóveis. As vantagens logísticas da IIRSA, além de proporcionar infraestrutura para empresas brasileiras, são utilizadas para acelerar o tempo de rotação do capital estrangeiro na região, o que faz dela um projeto de desenvolvimento integrado ao imperialismo. Luce afirma que a política externa brasileira não esta a serviço de um suposto interesse nacional e que seus esforços não são uma afronta ao imperialismo dominante. A inserção econômica e a integração regional promovidas pelo governo Lula na América do Sul não atendem somente a burguesia brasileira, como também ao capital estadunidense, cujo investimento vem crescendo na região. Esses projetos de inserção e integração de forma alguma são freios ao avanço das empresas estrangeiras, pelo contrário, são projetos de plataforma de exportação ou para uso intensivo dos recursos naturais pelo imperialismo dominante. Para Luce, o Estado brasileiro é subserviente aos interesses do capital Em Debat: Rev. Dig., ISSNe 1980-3532, Florianópolis, n. 7, p. 28-44, jan-jul, 2012. 
estadunidense ao mesmo tempo em que tenta galgar espaços para se tornar uma potência regional.

\section{O imperialismo brasileiro}

Virginia Fontes (2010), em O Brasil e o capital-imperialismo, caracteriza a atual fase de desenvolvimento do capitalismo brasileiro, especificamente, a internacionalização das empresas brasileiras, como imperialismo (ainda que subalterno). Segundo esta autora, o aumento da concentração de capitais (fusão das grandes empresas), a expansão do capital fora e dentro das fronteiras nacionais, e a acentuação da exploração da mão de obra e dos recursos naturais de outras formações sociais, principalmente da América Latina, são elementos que levaram a integração do Estado brasileiro ao grupo de países imperialistas.

O termo capital-imperialismo, segundo a autora, corresponde a uma retificação do conceito leninista de imperialismo. Trata-se da forma de desenvolvimento econômico, com predomínio do capital financeiro que se inicia após a Segunda Guerra Mundial e se aprofunda nesta primeira década do século XXI.

O processo de oligopolização do capital brasileiro se iniciou em meados da década de 1960, com a ditadura militar. Desde então, e com maior escala na última década, ocorreu um crescimento da exportação de produtos industrializados e exportação de capitais para outros países. No atual momento, Fontes destaca o papel do BNDES e da política externa como instrumentos de apoio e financiamento da internacionalização da economia brasileira. Além disso, Fontes destaca também o papel que os fundos de pensão passaram a representar nas ações das grandes empresas e no PIB brasileiro (aproximadamente 17\%).

No entanto, a autora ressalva que houve um processo de desnacionalização da economia brasileira devido à abertura comercial e às privatizações da década de 1990. A isso, soma-se o fato de que o capital-imperialismo teria contribuído para um "apassivamento" da classe trabalhadora por utilizar-se com maior intensidade da violência e do convencimento ideológico.

Fontes procura diferenciar-se de Ruy Mauro Marini, explicitando algumas divergências com o conceito de subimperialismo. Para ela, utilizar o conceito implica em admitir a premissa da inibição da demanda interna efetiva, o que não condiz com a 
atualidade. Pois a escassez de mercado interno não seria mais uma questão real na sociedade brasileira. Além disso, para a autora, o conceito de Marini não abarcaria as modificações estruturais decorrentes da nova ordem mundial pós Guerra Fria, da ascensão da economia chinesa e do novo papel do Estado brasileiro para ao favorecimento da expansão capital-imperialista.

\section{Considerações finais}

Apontamos algumas insuficiências e divergências que temos com estas três teses supramencionadas e alguns temas que necessitam de reflexões mais apuradas para que se possa entender o papel do Estado brasileiro no cenário internacional neste início de século XXI.

Em primeiro lugar, não se pode afirmar que o Estado brasileiro integre o grupo de países imperialistas como defende Virginia Fontes, pois o imperialismo pressupõe capacidade de uso da força militar para que se possa disputar mercados e explorações de outros territórios com outros Estados imperialistas. O Estado brasileiro não dispõe de tais recursos e não utiliza destes para auxiliar a sua expansão econômica internacional.

Em segundo lugar, houve algumas ações do Estado brasileiro que revelaram contradições pontuais com os Estados Unidos na cena política internacional e não uma cooperação antagônica, como afirma Luce, a saber: protesto contra a instalação de bases militares na Colômbia, o acolhimento de Manuel Zelaya na embaixada brasileira em Honduras, as negociações de enriquecimento de urânio no Irã, a intervenção no Iraque, entre outros. Além disso, cumpre-nos destacar que o papel que o Estado brasileiro cumpre hoje na América Latina é muito distinto do que foi no período da ditadura militar, momento no qual Marini elaborou o conceito de subimperialismo.

Em terceiro lugar, não se pode avaliar o papel que o Estado brasileiro desempenha nas demais formações sociais latino-americanas sem levar em conta o momento político e econômico destas formações sociais. Na nossa avaliação, os processos em curso na América Latina (em especial Bolívia, Venezuela, Equador, e outros), contam com o apoio do capital e do Estado brasileiro para implementarem políticas de desenvolvimento nacional, que, no atual contexto, visam reverter o quadro socio-político resultante das políticas neoliberais da década de 1990. Isso não elimina a possibilidade de que se criem dependências na dependência. No entanto, do ponto de 
vista político, não se pode negar que o Estado brasileiro, ainda que de forma contraditória, tem sido um aliado destes governos contra o domínio estadunidense na região, vide a atuação contra a instalação das bases militares na Colômbia, a posição sobre o Golpe de Estado em Honduras, entre outras. Segundo Matos:

[...] As obras de infra-estrutura (hidrelétricas, rodovias, ferrovias, oleodutos, gasodutos, telecomunicações) de empresas brasileiras na região, financiadas pelo BNDES, não deixam de ter efeitos positivos para a economia dos países em questões, a despeito das vantagens para o Brasil (bem maiores segundo os críticos). [...] Com isto, não estamos a defender que nossos vizinhos devem abraçar o expansionismo brasileiro porque, em termos de imperialismo, o Brasil seria melhor que os outros, mas é evidente que é mais fácil negociar/barganhar com um país periférico, sem grande poder de imposição (inclusive militar), que o contrário. Da parte do Brasil, o mais acertado seria orientar o expansionismo econômico (se for para seguir nesta direção) e sua política diplomática no sentido de estimular a solidariedade e complementaridade entre os países latino-americanos, colocando ênfase sobre a integração/cooperação, não sobre a exploração (mais força motriz e menos obstáculo) (SOUZA, 2010, p.50-51).

Em quarto lugar, na divisão internacional do trabalho o Brasil ainda ocupa uma posição subalterna: as exportações brasileiras se concentram em torno de commodities e de produtos de baixa densidade tecnológica e baixa intensidade de trabalho.

Em quinto lugar, ainda que tenha ocorrido uma internacionalização das empresas brasileiras, os investimentos externos diretos do Brasil no exterior somente em 2006 ultrapassaram $2 \%$ do PIB brasileiro (conforme o anexo I), enquanto a entrada de investimentos externos diretos no Brasil já ultrapassou 5\% do PIB brasileiro e se manteve acima de 2\% durante esta primeira década dos anos 2000 (conforme anexo II). Ou seja, o Brasil não superou o seu papel de economia dependente e recebe muito mais capital do que exporta. O investimento externo direto não é um fator exclusivo do Brasil, outras formações sociais dependentes também têm empresas que atuam em outros territórios (México, Argentina, Chile, entre outras). No entanto, o maior volume desse tipo de transação ainda se concentra nos países imperialistas.

Em sexto lugar, não acreditamos que as mudanças ocorridas na política externa e no financiamento estatal durante os governos Lula tenham sido resultado da construção de um novo tipo de Estado como defende Amado Luis Cervo e Valdez. Para nós, as mudanças estão ligadas às novas configurações e dinâmicas das classes sociais brasileiras.

Pensamos que é mais correto afirmar que o Estado e a economia brasileira são um Estado e uma economia dependentes frente ao imperialismo, o que não os impede de aproveitaram-se do maior desenvolvimento capitalista brasileiro para conquistar 
espaço nas economias menores e mais frágeis do continente. Do ponto de vista interno da dinâmica das classes sociais brasileiras -, essa política externa fortaleceu a grande burguesia interna brasileira empresas de extração mineral, agronegócio, usinas, energia elétrica, comunicações, construção civil, comércio, serviço, bancos, indústrias, empresas públicas, transporte e aviação e ao mesmo tempo atendeu a algumas demandas das classes dominadas, entre elas: aumento de políticas sociais, diminuição das taxas de desemprego e aumento do salário mínimo. Foram estes elementos que contribuíram para o reposicionamento do Estado brasileiro no cenário internacional nos últimos anos.

\section{Referências Bibliográficas}

ALEM, A. C.; CAVALCANTI, C. E. O BNDES e o Apoio à internacionalização das empresas brasileiras: algumas reflexões. Revista do BNDES, Rio de Janeiro, v. 12, n. 24, dez, 2005.

BRASIL. Banco Central do Brasil. Investimento Estrangeiro Direto. Disponível em $<$ http://www.bcb.gov.br/rex/IED/Port/ingressos/htms/index3.asp?idpai=invedir $>$. Acesso em: mar 2010.

CERVO, Amado Luiz e BUENO, Clodoaldo. História da politica exterior do Brasil. $3^{\mathrm{a}}$ ed. Brasília: Editora UnB, 2002.

CERVO, Amado Luiz. Inserção internacional: formação de conceitos brasileiros. São Paulo: Saraiva, 2007.

CHESNAIS, François. A mundialização do capital. São Paulo: Xamã, 1996.

FONTES, Virgínia. O Brasil e o capital-imperialismo: teoria e história. Rio de Janeiro: Universidade Federal do Rio de Janeiro, 2010.

FUNDAÇÃO DOM CABRAL. Investigación Global Players II. São Paulo: Fundação Dom Cabral, 2008. Disponível em

$<$ http://www.fdc.org.br/pt/pesquisa/internacionalizacao/Documents/Pesquisa_Global_P1 ayers_II.pdf $>$. Acesso em: mar 2010. 
Ranking das transnacionais brasileiras 2011. Disponível em:

<www.fdc.org.br>. Acesso em: out 2010

IGLESIAS, R. Os interesses empresariais brasileiros na América do Sul: investimentos diretos no exterior. Brasília: CNI, 2007.

KPMG - Tax Advisors/AssessoresTributários Ltda. Multinacionais brasileiras. [s. 1.]: KPMG, 2008. Disponível em <

http://www.kpmg.com.br/publicacoes/tax/Multinacionais_Brasileiras_08_portugues.pdf >. Acesso em: mar 2010.

LUCE, Mathias. 2007. O subimperialismo brasileiro revisitado: a politica de integração regional do governo Lula (2003-2007). 136f. Dissertação (Mestrado em Relações Internacionais)-Instituto de Filosofia e Ciências Humanas, Universidade Federal do Rio Grande do Sul, Porto Alegre

MARINI, Ruy Mauro. Subdesarrollo y revolucion. México, DF: Siglo Veintiuno, 1980.

La acumulación capitalista mundial y el subimperialismo. Cuadernos

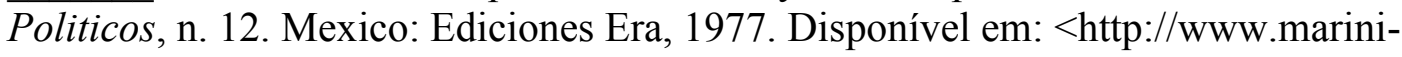
escritos.unam.mx/006_acumulacion_es.htm > . Acesso em: outubro de 2011.

NOVOA, L. F. O Brasil e seu "desdobramento": o papel central do BNDES na expansão das empresas transnacionais brasileiras na América do Sul. Transnacionais Brasileiras: um debate necessário. São Paulo: Expressão Popular, 2009.

PAULANI, Leda. Brasil delivery. São Paulo: Boitempo, 2008.

SOBEET/Valor Econômico. Multinacionais Brasileiras. São Paulo: Valor Econômico, 2009.

SOUZA, Angelita Matos. O expansionismo nos governos Lula e no BNDES. Meridiano 47, vol. 11, n. 120, jul.-ago 2010.

VALDEZ, Robinson. 2011. A internacionalização do BNDES no governo Lula. $132 \mathrm{f}$. Dissertação (Mestrado em Relações Internacionais)-Instituto de Filosofia e Ciências Humanas, Universidade Federal do Rio Grande do Sul, Porto Alegre. 


\section{Anexo I}
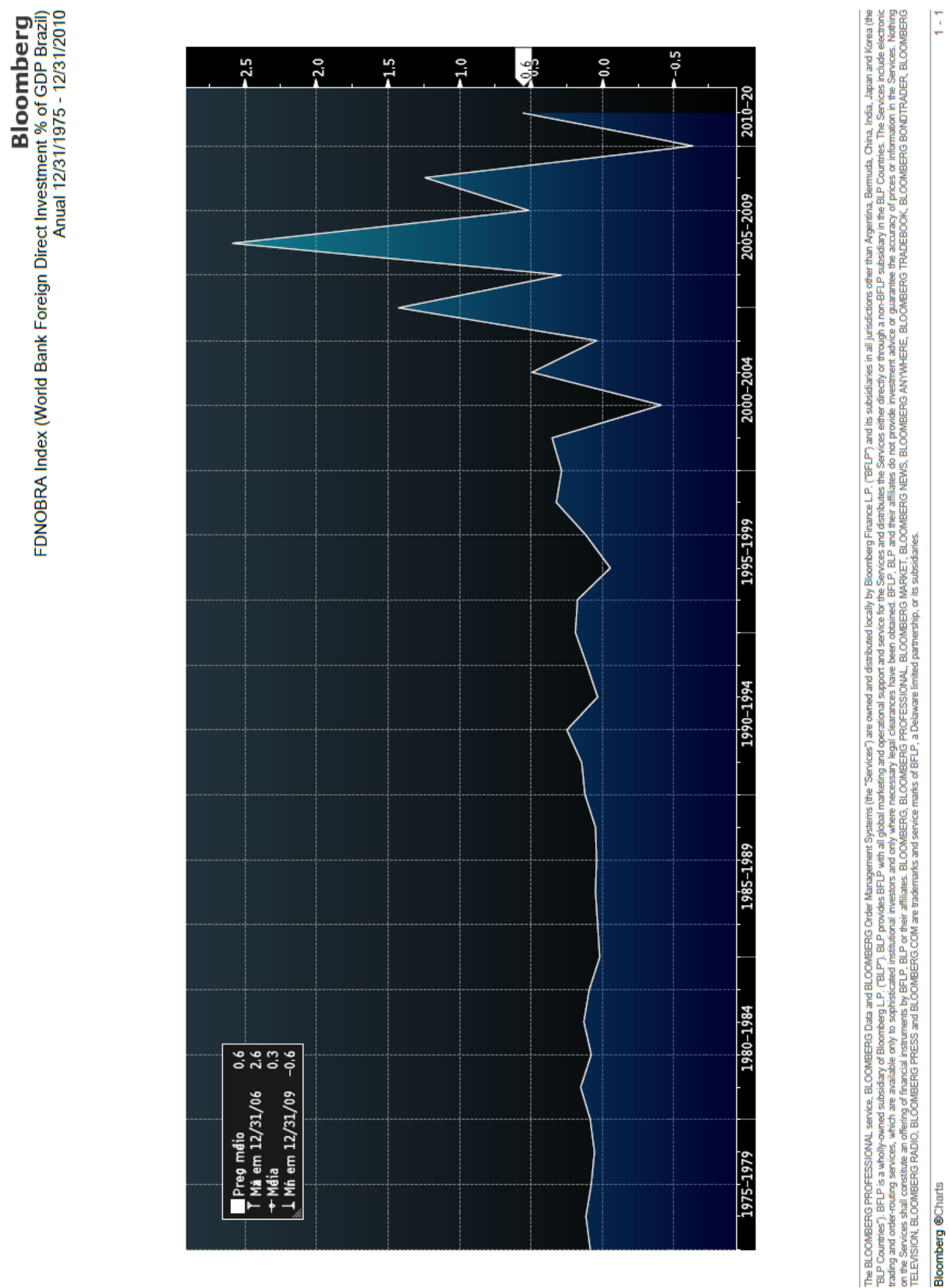

Em Debat: Rev. Dig., ISSNe 1980-3532, Florianópolis, n. 7, p. 28-44, jan-jul, 2012. 


\section{Anexo II}
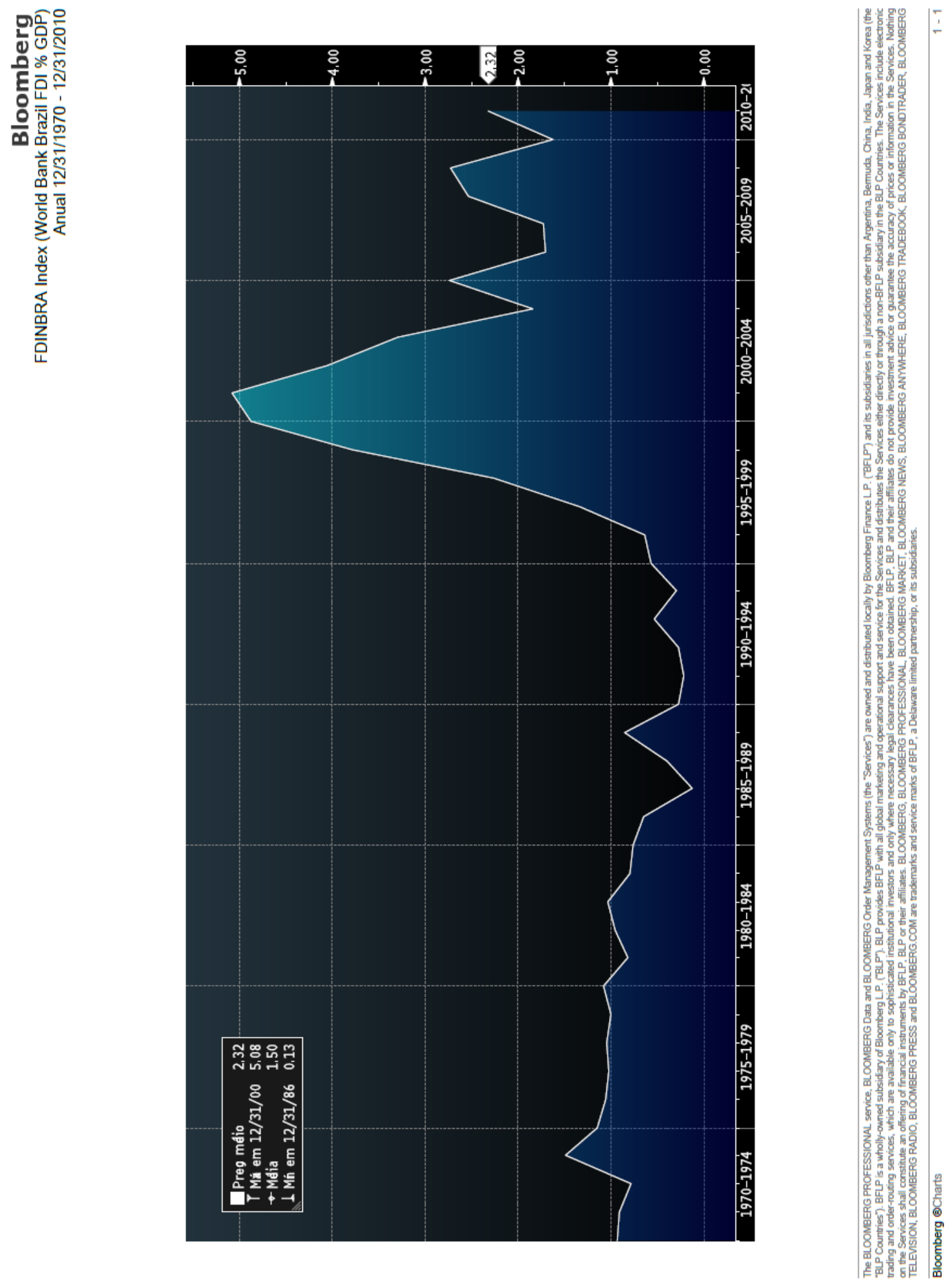

Em Debat: Rev. Dig., ISSNe 1980-3532, Florianópolis, n. 7, p. 28-44, jan-jul, 2012. 